\section{Occupational asthma due to polyethylene shrink wrapping (paper wrapper's asthma)}

\author{
Paul F G Gannon, P Sherwood Burge, \\ G F A Benfield
}

\begin{abstract}
Occupational asthma due to the pyrolysis products of polyvinyl chloride (PVC) produced by shrink wrapping processes has previously been reported. The first case of occupational asthma in a shrink wrap worker using a different plastic, polyethylene, is reported; the association was confirmed by specific bronchial provocation testing.
\end{abstract}

Meat wrapper's asthma due to the thermal degradation products produced by polyvinyl chloride (PVC) used for shrink wrapping was first described in $1973 .{ }^{1}$ Subsequent work has implicated acid anhydrides (from label adhesives) and pyrolysis products from soyabean oil incorporated into the PVC wrapping ${ }^{2}$ as possible causative agents. Occupational asthma caused by the pyrolysis products of polyethylene has been suggested ${ }^{3}$ but not confirmed. We describe a worker with occupational asthma due to polyethylene, the association being confirmed by specific bronchial provocation testing.

\section{Case report}

An 18 year old paper packer, who was atopic and a non-smoker and had pre-existing well controlled asthma, started work on a shrink wrap machine. The machine heats paper goods sealed in pure polyethylene sheeting (EXL Shrink 1, CFS 450/900 Sanders Polyfilm) briefly to $166^{\circ} \mathrm{C}$, when the wrapping partially shrinks. The polyethylene contained no fillers, stabilisers, or bonding agents. Two weeks after starting to use this machine he began to get attacks of asthma six to seven hours after starting work. The symptoms improved on

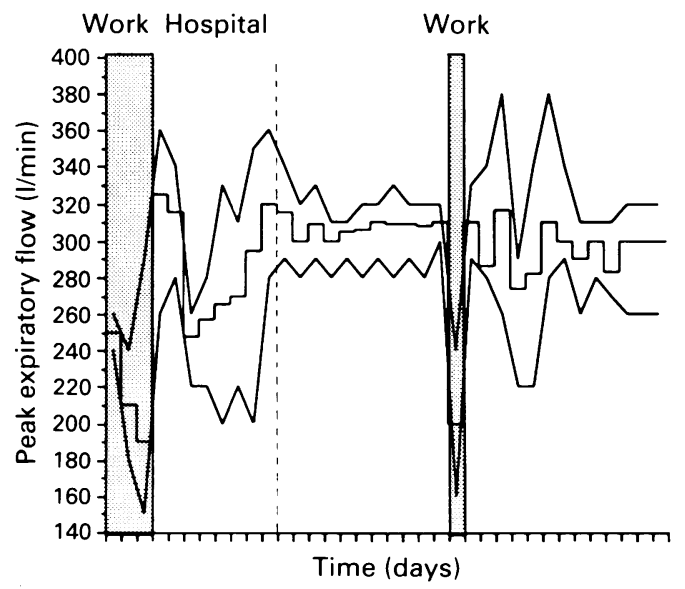

Figure 1 Results of occupational type serial peak flow tests: maximum, mean, and minimum values on work days, during a hospital visit, and at home.

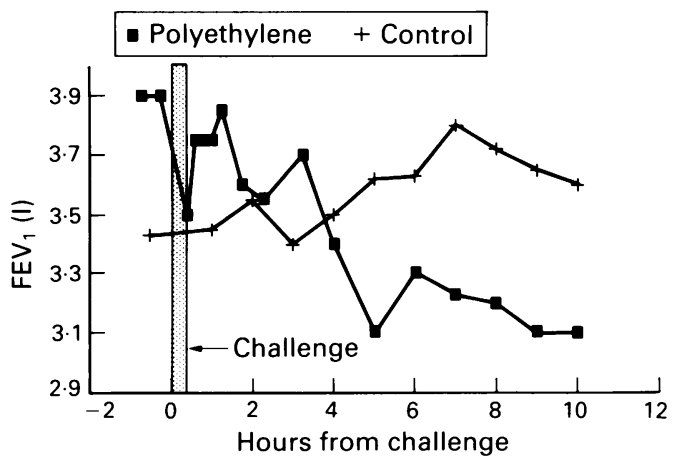

Figure 2 Results of specific bronchial challenge testing with polyethylene.

days when he was away from work. He had several periods of illness that kept him off work and on the last occasion required hospital admission after 30 minutes at work. After initial recovery his forced expiratory volume in one second $\left(\mathrm{FEV}_{1}\right)$ and forced vital capacity (FVC) were $2 \cdot 2$ (predicted 3.6 ) 1 and 2.44 (predicted 4.28) 1 respectively; histamine challenge testing showed the provocative dose of histamine causing a $20 \%$ fall in $\mathrm{FEV}_{1}\left(\mathrm{PD}_{20}\right)$ to be $0.083 \mu \mathrm{mol}$, indicating pronounced bronchial hyperreactivity.

Serial peak flow measurements showed a pronounced fall on his return to work (fig 1). Specific bronchial challenge testing consisting of an eight minute exposure to polyethylene heated to $76^{\circ} \mathrm{C}$ in a heating block caused a transitory early bronchoconstrictor' response followed by a more pronounced late response (fig 2). No reaction was seen on a control day. Occupational asthma was diagnosed and the worker was removed from exposure. His symptoms and spirometric values improved considerably $\left(\mathrm{FEV}_{1} 4.011\right.$ and FVC 4.271 six months after exposure ceased). His $\mathrm{PD}_{20}$ histamine is unchanged $(0.08 \mu \mathrm{mol} 18$ months after exposure ceased). He now has minimal asthma and is in full time employment.

\section{Discussion}

The agent causing this patient's occupational asthma is unknown. The manufacturers suggest that carbon monoxide and formaldehyde could be released at temperatures above $300^{\circ} \mathrm{C}$ and acrolein and acetic acid at temperatures above $400^{\circ} \mathrm{C}$. Formaldehyde is recognised as causing occupation asthma. ${ }^{4}$ These temperatures may be reached if the polyethylene film adheres to the shrink wrap machine heater. This would not explain why an asthmatic reaction was observed after bronchial challenge at lower temperatures, however.

Polyethylene shrink wrapping is used widely as a final stage of packaging products in many manufacturing processes. It should be borne in mind in the search for a cause of work related symptoms in workers from manufacturing industries.

1 Sokal WN, Aclony Y, Beall GN. Meat wrapper's asthma-a new syndrome? JAMA 1973;226:639-41.

2 Pauli G, Bessot JC, Kofferschmitt MC, Lingot G, Wendling $\mathrm{R}$, Ducos $\mathrm{P}$, et al. Meat wrapper's asthma: identification of causal agents. Clin Allergy 1980;10:236-9.

3 Skerfving S, Akesson B, Simonsson BG "Meat wrapper's asthma" caused by thermal degradation products of polyethylene [letter]. Lancet 1980;i:211.

4 Vaughan WT. The practice of allergy. St Louis: Mosby, 1939:677.
Reprint requests to: Dr P F G Gannon 